Surgery for

Congenital Heart

Disease

\title{
Cardiac surgery in infants with low birth weight is associated with increased mortality: Analysis of the Society of Thoracic Surgeons Congenital Heart Database
}

Christopher L. Curzon, DO, ${ }^{a}$ Sarah Milford-Beland, MS, ${ }^{\text {b }}$ Jennifer S. Li, MD, MHS, ${ }^{\text {a,b }}$ Sean M. O'Brien, PhD, ${ }^{\text {b }}$ Jeffrey Phillip Jacobs, MD, ${ }^{c}$ Marshall Lewis Jacobs, MD, ${ }^{d}$ Karl F. Welke, MD, ${ }^{e}$ Andrew J. Lodge, MD, ${ }^{f}$ Eric D. Peterson, MD, MPH, and James Jaggers, $M^{f}$

From the Department of Pediatrics, Division of Pediatric Cardiology, ${ }^{a}$ Duke University Medical Center, Durham, NC; the Duke Clinical Research Institute, ${ }^{\mathrm{b}}$ Durham, NC: the Congenital Heart Institute of Florida (CHIF), ${ }^{\mathrm{C}}$ University of South Florida, All Children's Hospital; Pediatric Cardiovascular Surgery, ${ }^{\mathrm{d}}$ St Christopher's Hospital for Children, Philadelphia, Pa; the Division of Cardiothoracic Surgery, ${ }^{\mathrm{e}}$ Oregon Health and Science University, Portland, Ore; and the Division of Cardiovascular Surgery, Duke University Medical Center, Durham, NC.

Read at the Eighty-seventh Annual Meeting of The American Association for Thoracic Surgery, Washington, DC, May 5-9, 2007.

Received for publication May 4, 2007; revisions received Aug 30, 2007; accepted for publication Sept 14, 2007.

Address for reprints: James Jaggers, MD, Box 3474, DUMC, Durham, NC 27710 (E-mail: james.jaggers@duke.edu).

J Thorac Cardiovasc Surg 2008;135:546-51 0022-5223/\$34.00

Copyright (C) 2008 by The American Association for Thoracic Surgery

doi:10.1016/j.jtcvs.2007.09.068
Objective: The evaluation of operative mortality risk for cardiac surgery in infants with low weight is limited. To determine whether low weight is a risk factor for increased mortality, we reviewed the experience within the Society of Thoracic Surgeons Congenital Heart Surgery Database of infants who have undergone surgical correction or palliation for congenital heart disease.

Methods: We analyzed mortality in 3022 infants ages 0 to 90 days weighing 1 to $2.5 \mathrm{~kg}(\mathrm{n}=517)$ and greater than 2.5 to $4 \mathrm{~kg}(\mathrm{n}=2505)$ who underwent cardiac surgery from 2002 through 2004 at 32 participating centers. Patients were grouped according to the primary procedure performed and analyzed according to their weight at the time of surgical intervention. Patients were also analyzed according to Risk Adjustment for Congenital Heart Surgery-1 and Aristotle Basic Complexity scores.

Results: Compared with infants weighing 2.5 to $4 \mathrm{~kg}$, infants weighing less than 2.5 $\mathrm{kg}$ had a significantly higher mortality for the following operations: repair of coarctation of the aorta, total anomalous pulmonary venous connection repair, arterial switch procedure, systemic to pulmonary artery shunt, and the Norwood procedure. Lower infant weight remained strongly associated with mortality risk after stratifying the population by Risk Adjustment for Congenital Heart Surgery-1 levels 2 through 6 and Aristotle Basic Complexity levels 2 through 4.

Conclusions: Low weight at the time of surgical intervention is associated with increased mortality in patients undergoing several types of cardiovascular procedures. These data do not allow assessment of specific risks or benefits of any particular treatment strategy. However, they do support the need for prospective analysis of specific treatment strategies for these high-risk patients.

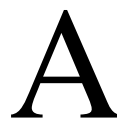
lthough outcomes for repair of congenital heart defects in neonates have improved significantly over the last 10 years, low-weight infants remain a challenging population. Despite recent single-institution reports ${ }^{1-5}$ of improved survival in this difficult group, the significance of weight as a risk factor for mortality remains unclear. Studies that report surgical outcomes in low-weight infants 


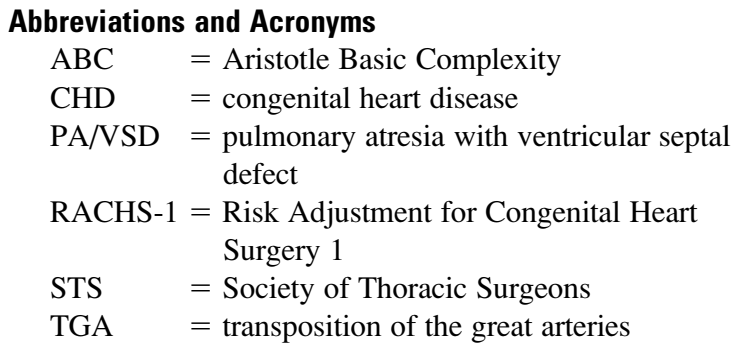

have been limited to single institutions with limited numbers of patients. These studies typically examine weight as an independent risk factor without including a comparison group of normal-weight infants. In this study we used of the Society of Thoracic Surgeons (STS) Congenital Heart Surgery Database to evaluate the hypothesis that low-weight infants have increased operative mortality when compared with children of normal weight with similar defects.

\section{Materials and Methods \\ Database}

The STS Congenital Heart Surgery Database collects operative procedure-related data on neonates, infants, children, and adults undergoing operations for congenital heart anomalies. In 2004, 34 institutions contributed data to the congenital heart database. The Duke Clinical Research Institute serves as the data collection and management organization for all of the STS National Databases. Data collected within the Congenital Heart Surgery Database include basic demographic information, anatomic diagnosis, associated noncardiac abnormalities, preoperative risk factors, intraoperative details, surgical procedure performed, postoperative complications, and operative mortality.

\section{Study Population}

Using the Congenital Heart Surgery Database, we analyzed mortality in infants up to 90 days of age who underwent cardiovascular surgery between January 2002 and December 2004. Data from participating centers with greater than $10 \%$ missing data for discharge mortality or postoperative length of stay were excluded. This left 18,253 patients from 32 centers with complete diagnosis and procedure data for the first cardiovascular operation during their index admission. From these, we excluded patients with age greater than 90 days $(\mathrm{n}=11,681)$, weight less than $1 \mathrm{~kg}$ or greater than $4 \mathrm{~kg}$ $(\mathrm{n}=1743)$, missing primary procedure data $(\mathrm{n}=1760)$, or missing discharge mortality status $(n=47)$. The remaining patient population for analysis was 3022 .

Patients were further grouped according to primary cardiovascular diagnosis and procedures (Table 1). The primary procedure was defined as the procedure with the highest Aristotle Basic Complexity $(\mathrm{ABC})$ score. If there were multiple procedures with equal complexity scores listed, the procedure designated as the primary procedure on the data collection form was used. Because the Risk Adjustment for Congenital Heart Surgery 1 (RACHS-1) score was not a required field in the database in 2004, this score was assigned by the investigators. ${ }^{6}$
TABLE 1. Cardiac diagnoses

\begin{tabular}{lc}
\hline \multicolumn{1}{c}{ Cardiac anomaly } & $\mathbf{n}$ \\
\hline Single ventricle & 847 \\
- Hypoplastic left heart syndrome (594) & \\
- Tricuspid atresia (99) & \\
- Double-inlet left ventricle (50) & \\
- Unbalanced AVSD (17) & \\
- Heterotaxy syndromes (34) & \\
- Single ventricle, NOS (53) & 212 \\
TGA, intact ventricular septum & 133 \\
TGA, VSD & 247 \\
VSD & 102 \\
Truncus arteriosus & 226 \\
Total anomalous pulmonary venous connection & 196 \\
Tetralogy of Fallot & 128 \\
Pulmonary atresia, intact ventricular septum & 137 \\
Pulmonary atresia, VSD & 594 \\
Coarctation of aorta & 110 \\
Interrupted aortic arch &
\end{tabular}

AVSD, Atrioventricular septal defect; NOS, not otherwise specified; TGA, transposition of the great arteries; VSD, ventricular septal defect.

\section{Statistics}

Patients were classified according to weight at the time of surgical intervention: 1 to $2.5 \mathrm{~kg}(\mathrm{n}=517)$ and greater than 2.5 to $4 \mathrm{~kg}$ $(\mathrm{n}=2505)$. Sex, ethnicity, and age were compared between patients in each weight category (Table 2). Age was described as a median and interquartile range (IQR; defined as 25 th to 75 th percentile), and sex and ethnicity were described as frequencies. The distribution of age was compared by using a stratum-adjusted Wilcoxon rank-sum test, although sex and ethnicity were compared by using stratum-adjusted $\chi^{2}$ tests. Mortality rates were calculated by weight category for all combinations of diagnoses and procedures with a sample size of at least 15 . Relative risks and approximate $95 \%$ confidence intervals were constructed to compare mortality risk between groups. The hypothesis of no association between weight group and mortality was assessed by using a $\chi^{2}$ test. Identical analyses were performed by using stratification with the RACHS-1

TABLE 2. Patient demographics

\begin{tabular}{lccc}
\hline \multicolumn{1}{c}{ Characteristic } & $\begin{array}{c}\mathbf{1 - 2 . 5} \mathbf{~ k g}, \\
\mathbf{n}=\mathbf{5 1 7}(\%)\end{array}$ & $\begin{array}{c}\mathbf{2 . 5}-\mathbf{4 . 0} \mathbf{~ k g}, \\
\mathbf{n}=\mathbf{2 5 0 5}(\%)\end{array}$ & $\boldsymbol{P}$ value \\
\hline Race & & & \\
$\quad$ Other & $47(9.1)$ & $198(7.9)$ & .19 \\
Native American & $1(0.2)$ & $9(0.4)$ & \\
Asian & $11(2.1)$ & $55(2.2)$ & \\
Hispanic & $74(14.3)$ & $416(16.6)$ & \\
$\quad$ Black & $67(13.0)$ & $240(9.6)$ & \\
$\quad$ Caucasian & $237(45.8)$ & $1236(49.3)$ & \\
Sex & & & \\
$\quad$ Male & $275(53.2)$ & $1446(57.7)$ & .07 \\
Female & $242(46.8)$ & $1,059(42.3)$ & \\
Age (d) & & & \\
$\quad$ Median & $9.00(5.00-17.0)$ & $7.00(4.00-19.0)$ & .34 \\
\hline
\end{tabular}


TABLE 3. Mortality data, diagnostic-procedure groups

\begin{tabular}{|c|c|c|c|c|c|}
\hline & $\begin{array}{c}\text { Mortality rate, } \\
\text { overall ( } n=3022)\end{array}$ & $\begin{array}{l}\text { Mortality rate, } 1-2.5 \mathrm{~kg} \\
\quad(\mathrm{n}=517)\end{array}$ & $\begin{array}{l}\text { Mortality rate } 2.5-4 \text { kg } \\
\quad(\mathrm{n}=2505)\end{array}$ & Risk ratio (95\% Cl) & $P$ value* \\
\hline \multicolumn{6}{|l|}{ Single ventricle } \\
\hline Norwood & $22.4(584)$ & $30.0(90)$ & 21.1 (494) & $1.43(1.00-2.04)$ & .03 \\
\hline Conduit/shunt & 10.5 (191) & $24.4(45)$ & $6.2(146)$ & $3.97(1.76-8.96)$ & $<.01$ \\
\hline \multicolumn{6}{|l|}{ TGA/IVS } \\
\hline ASO & $3.3(212)$ & $11.8(17)$ & $2.6(195)$ & $4.59(0.96-21.90)$ & .01 \\
\hline \multicolumn{6}{|l|}{ TAPVC } \\
\hline Repair & $12.0(226)$ & $29.2(24)$ & $9.9(202)$ & $2.95(1.39-6.23)$ & .01 \\
\hline \multicolumn{6}{|l|}{ PA/VSD } \\
\hline Shunt & 6.1 (99) & $14.8(27)$ & $2.8(72)$ & $5.33(1.04-27.46)$ & .02 \\
\hline \multicolumn{6}{|l|}{ Coarctation } \\
\hline Arch repair & $3.5(594)$ & $7.1(112)$ & $2.7(482)$ & $2.65(1.12-6.24)$ & $<.01$ \\
\hline \multicolumn{6}{|l|}{ Single ventricle } \\
\hline Atrial septectomy & $40(20)$ & $80.0(5)$ & $26.7(15)$ & $3.00(1.16-7.73)$ & .32 \\
\hline PA band & $9.6(52)$ & $0(9)$ & $11.6(43)$ & NA & .28 \\
\hline \multicolumn{6}{|l|}{ TGA/VSD } \\
\hline \multicolumn{6}{|l|}{ PA/VSD } \\
\hline Repair & $7.9(38)$ & $12.5(8)$ & $6.7(30)$ & $1.88(0.19-18.15)$ & .39 \\
\hline \multicolumn{6}{|l|}{ PA/IVS } \\
\hline RVOT repair & $5.6(36)$ & $0(6)$ & $6.7(30)$ & NA & NA \\
\hline Shunt palliation & $15.2(92)$ & $22.7(22)$ & $12.9(70)$ & $1.77(0.66-4.72)$ & .48 \\
\hline \multicolumn{6}{|l|}{ VSD } \\
\hline Primary repair & $1.7(232)$ & $8.0(25)$ & $1.0(207)$ & $8.28(1.22-56.23)$ & .33 \\
\hline PA band & $0(15)$ & $0.0(6)$ & $0.0(9)$ & NA & NA \\
\hline \multicolumn{6}{|l|}{ AVSD } \\
\hline Primary repair & $4.1(73)$ & $50.0(2)$ & $2.8(71)$ & $17.75(2.54-124.28)$ & .08 \\
\hline PA band & $5.9(17)$ & $0.0(2)$ & $6.7(15)$ & NA & NA \\
\hline \multicolumn{6}{|l|}{ Truncus arteriosus } \\
\hline Repair & $12.8(102)$ & $17.4(23)$ & $11.4(79)$ & $1.53(0.52-4.51)$ & .53 \\
\hline \multicolumn{6}{|l|}{ Tetralogy of Fallot } \\
\hline Primary repair & 6.1 (99) & $5.3(19)$ & $6.3(80)$ & $0.84(0.10-6.79)$ & .61 \\
\hline Shunt palliation & $8.3(97)$ & $7.4(27)$ & $8.6(70)$ & $0.86(0.19-4.02)$ & .58 \\
\hline \multicolumn{6}{|l|}{ Interrupted arch } \\
\hline Repair & $9.1(110)$ & $12.9(31)$ & 7.6 (79) & $1.70(0.51-5.61)$ & .69 \\
\hline
\end{tabular}

$\mathrm{Cl}$, Confidence interval; TGA/IVS, transposition of the great arteries/intact ventricular septum; $A S O$, atrial switch operation; TAPVC, total anomalous pulmonary venous connection; $P A / V S D$, pulmonary atresia/ventricular septal defect; $P A$ band, pulmonary artery band; TGA/VSD, transposition of the great arteries/ ventricular septal defect; $P A / I V S$, pulmonary atresia/intact ventricular septum; RVOT, right ventricular outflow tract; $A V S D$, atrioventricular septal defect. ${ }^{*} P$ value is adjusted for hospital identity. Confidence intervals were not calculated for nonsignificant categories.

system and ABC scores. SAS Statistical software (Cary, NC) was used for analysis.

\section{Results}

A total of 3022 patients were evaluated. In the group weighing $2.5 \mathrm{~kg}$ or more, there were a total of 517 patients, and in the group weighing more than 2.5 to $4.0 \mathrm{~kg}$, there were 2505 patients. The cardiac diagnoses of the groups are listed in Table 1 . There were no differences between sex, ethnicity, or age between the groups (Table 2).

Patients undergoing repair of total anomalous pulmonary venous connection (29.2\% vs $9.9 \%$ ), coarctation of the aorta repair $(7.1 \%$ vs $2.7 \%)$, arterial switch procedure for transposition of the great arteries (TGA; $11.8 \%$ vs $2.6 \%$ ), systemic to pulmonary artery shunt placement for pulmonary atresia with ventricular septal defect (PA/VSD; $14.8 \%$ vs $2.8 \%$ ), and systemic to pulmonary artery shunt $(24.4 \%$ vs $6.2 \%)$ and the Norwood procedure $(30 \%$ vs $21.1 \%$ ) for other singleventricle diagnoses demonstrated increased risk of mortality for those infants weighing $2.5 \mathrm{~kg}$ or more (Table 3). Patients with PA/VSD and TGA with intact ventricular septum weighing less than $2.5 \mathrm{~kg}$ had the highest risk ratios. For all other diagnosis-procedure categories analyzed, there was no statistically significant difference in mortality for those infants weighing less than $2.5 \mathrm{~kg}$. The inverse association between infant weight and outcomes persisted after we stratified the population using the RACHS- 1 and ABC scoring systems. Weight less than $2.5 \mathrm{~kg}$ was consistently 
TABLE 4. Mortality data by complexity scoring

\begin{tabular}{ccccr}
\hline & $\begin{array}{c}\text { Mortality rate, } \\
\mathbf{1 - 2 . 5} \mathbf{~ k g} \\
(\mathbf{n}=\mathbf{5 1 7})\end{array}$ & $\begin{array}{c}\text { Mortality rate, } \\
\mathbf{2 . 5}-\mathbf{4} \mathbf{~ k g} \\
(\mathbf{n}=\mathbf{2 5 0 5})\end{array}$ & $\begin{array}{c}\text { Risk ratio } \\
(\mathbf{9 5 \%} \mathbf{~ C l})\end{array}$ & $\begin{array}{c}\boldsymbol{P} \\
\text { value }\end{array}$ \\
\hline RACHS-1 & & & & \\
2 & $5.0(139)$ & $2.4(709)$ & $2.1(0.89-4.97)$ & .03 \\
3 & $14.2(183)$ & $5.6(840)$ & $2.5(1.62-3.99)$ & $<.01$ \\
4 & $21.9(105)$ & $9.7(462)$ & $2.3(1.43-3.55)$ & $<.01$ \\
6 & $30.0(90)$ & $21.1(494)$ & $1.4(1.00-2.04)$ & .03 \\
Aristotle & & & & \\
1 & $80.0(5)$ & $26.7(15)$ & $3.0(1.16-7.73)$ & .32 \\
2 & $11.7(222)$ & $5.5(876)$ & $2.1(1.36-3.37)$ & $<.01$ \\
3 & $13.6(88)$ & $5.2(544)$ & $2.7(1.40-5.01)$ & $<.01$ \\
4 & $20.78(178)$ & $13.6(965)$ & $1.5(1.10-2.13)$ & $<.01$ \\
Risk level & $16.7(24)$ & $1.9(105)$ & $8.75(1.7-45.04)$ & .08 \\
missing & & & & \\
\hline
\end{tabular}

RACHS-1, Risk Adjustment for Congenital Heart Surgery 1.

associated with 1.5 to 3.0 times higher mortality risk in all levels of RACHS-1 and ABC scoring, with the exception of $A B C$ level 1 (Table 4).

\section{Discussion}

Significant advances in surgical techniques and conduct of cardiopulmonary bypass have resulted in improved survival for even the smallest of patients. These advancements now allow surgeons to routinely perform definitive open cardiac procedures in neonates and infants weighing less than 2500 g. In the past, only palliative procedures or medical therapy might have been available to such patients.

The New England Regional Infant Cardiac Program, ${ }^{7}$ as well as Kramer and colleagues, ${ }^{8}$ demonstrated infants with congenital heart disease (CHD) were more likely to be small for gestational age or of low birth weight when compared with normal-weight infants. The incidence of being small for gestational age is $15 \%$ and that of low birth weight is $8.6 \%$ in infants with CHD compared with $4.5 \%$ and $6 \%$, respectively, in the healthy population. After adjusting for other potential confounding factors, the New England Regional Infant Cardiac Program concluded that there was a direct relationship between mortality and birth weight of less than $2 \mathrm{~kg}$. They assigned a prognostic value from 1 (best) to 4 (worst) in an attempt to risk stratify the various diagnoses and then calculated crude 1-year mortality rates according to these diagnostic severity groups, analyzing infants with a birth weight of less than $2 \mathrm{~kg}$ as a group of interest. Calculated mortality rates in the less than $2-\mathrm{kg}$ group ranged from $70 \%$ to $100 \%$ compared with $27 \%$ to $86 \%$ for the same diagnostic severity groups. ${ }^{7}$ Since that time, there have been multiple attempts to further examine the relationship between birth weight and mortality for infants with CHD. However, these studies have been limited to single institutions with limited numbers of patients or have examined weight as an inde- pendent risk factor without careful case-control procedures. ${ }^{1-5}$ Analysis of the STS Congenital Heart Database affords the opportunity to further examine these clinical questions with sample sizes larger than has been previously possible.

The combination of low birth weight, prematurity, and CHD makes the management of these patients challenging. It is unclear whether a strategy of medical management and deferment of surgical intervention is beneficial over more expeditious intervention. Preoperative management of infants with ductal-dependent pulmonary or systemic blood flow requires intravenous prostaglandin $\mathrm{E}_{1}$ and carries the associated risks of infection, apnea, vasodilation, seizures, and necrotizing enterocolitis. Furthermore, the altered physiologic state of unrepaired CHD leads to increased energy expenditure, failure to thrive, and further difficulty in weight gain. The long-term effects of abnormal cardiovascular physiology, including volume overload and hypoxemia, are difficult to quantify. ${ }^{9}$ Conventional surgical wisdom might suggest that delaying surgical intervention until a higher weight is attained might decrease the risk of bypass-related morbidities, including intracranial hemorrhage, renal dysfunction, and coagulopathy. At the present time, however, there are insufficient data to predict the risk/benefit ratio of deferring surgical intervention until some arbitrary weight gain. In a small series of patients, Chang and colleagues ${ }^{10}$ demonstrated not only that this management strategy was ineffective but that in their experience it was associated with increased mortality. In another single-institution study by Reddy and associates, ${ }^{4}$ an analysis of approximately 100 infants weighing less than $2.5 \mathrm{~kg}$ led to the inference that delaying repair conferred higher preoperative morbidity without any associated benefit. Unfortunately, given the limitations of the present study, we are unable to adequately address and answer the question of whether a strategy of deferring surgical intervention for weight gain is beneficial. Further prospective investigation to determine how the risk of delaying surgical intervention on these patients compares with the risk of repair is still necessary.

In this investigation we have demonstrated an increased mortality associated with low-weight infants undergoing specific cardiovascular procedures for coarctation of the aorta, total anomalous pulmonary venous connection, TGA, PA/ VSD, and the presence of a single ventricle. Roussin and coworkers ${ }^{11}$ demonstrated similar findings, with operative mortality of $16 \%$ in patients weighing less than $2000 \mathrm{~g}$ with TGA undergoing the arterial switch operation. Overall operative mortality in patients with hypoplastic left heart syndrome is approximately $20 \%$, whereas some investigations have shown a mortality rate in low-weight patients to be as high as $45 \% .^{12}$ In the present investigation the mortality rate for low-weight patients undergoing a Norwood procedure was $30 \%$. Findings in our study would suggest that there is a subset of low-weight patients with increased risk of operative mortality. At the same time, the data suggest that some 
cardiovascular procedures can be performed without substantial difference in mortality.

Both the ABC and RACHS-1 scoring systems were designed to facilitate meaningful comparisons of outcomes in children undergoing surgical intervention for CHD. ${ }^{6,13}$ Analysis of mortality based on either of these scoring systems and stratified by weight has not previously been performed. Mortality rates for nearly all infants of weight less than 2.5 $\mathrm{kg}$ is increased throughout the various levels of complexity, as stratified by using both of these tools. The high absolute mortality rates for both weight categories in $\mathrm{ABC}$ level 1 were not statistically significant and lack power for meaningful interpretation of these data because of the small sample sizes.

Further stratification within the diagnosis-procedure categories, as well as the RACHS- 1 and ABC scores, by age at the time of surgical intervention was not feasible because of the small sample size of low-weight patients. For lowweight patients undergoing a Norwood procedure, there was a trend toward increased mortality for those who were taken to surgical intervention within the first week of life. However, within this age stratification, overall sample sizes were too small to provide meaningful data.

The limitations of the study are primarily related to the observational and voluntary nature of the database, which is still in evolution. The STS databases are observational and were established principally for the purpose of health care quality improvement. We investigated the feasibility of adjusting for potential confounding variables, such as preoperative risk factors and associated noncardiac anomalies. Unfortunately, attempts at a multivariate analysis to examine the interaction for these potential confounders were unsuccessful because of a high percentage of missing data. Also, it was not possible to determine whether some patients had been operated on after a period of nonoperative management or if there was any survival benefit to this approach. Because the STS Congenital Database is a procedural database, patients who did not survive to a surgical procedure are not included. Many of the previous reports are based on birth weight; however, at the time of the data harvest used in our analysis, birth weight and gestational age were not components of the data set, thereby making parallel comparisons difficult. Additionally, the inability to stratify by age within both diagnosis-procedure and risk scoring made analysis of the effect of delayed intervention with medical management infeasible. Therefore this study cannot make any conclusions or recommendations regarding any particular management strategy regarding low-birth-weight infants with CHD.

Low weight at the time of surgical intervention is associated with increased mortality for repair of coarctation of the aorta, total anomalous pulmonary venous connection, arterial switch procedure for TGA, systemic to pulmonary artery shunt placement for PA/VSD, and systemic to pulmonary artery shunt and the Norwood procedure for single-ventricle palliation. Notwithstanding several important limitations, this study is nonetheless one of the largest to date to examine the relationship between low birth weight and the risk of operative mortality in congenital heart surgery. It highlights the need for prospective analyses of specific treatment strategies as a means of improving outcomes for these high-risk patients.

\section{References}

1. Bove T, Francois K, De Groote K, Suys B, De Wolf D, Verhaaren H, et al. Outcome analysis of major cardiac operations in low weight neonates. Ann Thorac Surg. 2004;78:181-7.

2. Oppido G, Napoleone CP, Formigari R, Gabbieri D, Pacini D, Frascaroli G, et al. Outcome of cardiac surgery in low birth weight and premature infants. Eur J Cardiothorac Surg. 2004;26:44-53.

3. Pawade A, Waterson K, Laussen P, Karl TR, Mee RB. Cardiopulmonary bypass in neonates weighing less than $2.5 \mathrm{~kg}$ : analysis of the risk factors for early and late mortality. J Card Surg. 1993;8:1-8.

4. Reddy VM, McElhinney DB, Sagrado T, Parry AJ, Teitel DF, Hanley FL. Results of 102 cases of complete repair of congenital heart defects in patients weighing 700 to 2500 grams. J Thorac Cardiovasc Surg. 1999; 117:324-31.

5. Rossi AF, Seiden HS, Sadeghi AM, Nguyen KH, Quintana CS, Gross RP, et al. The outcome of cardiac operations in infants weighing two kilograms or less. J Thorac Cardiovasc Surg. 1998;116:28-35.

6. Jenkins KJ, Gauvreau K, Newburger JW, Spray TL, Moller JH, Iezzoni LI. Consensus-based method for risk adjustment for surgery for congenital heart disease. J Thorac Cardiovasc Surg. 2002;123: $110-8$.

7. Report of the New England Regional Infant Cardiac Program. Pediatrics. 1980;65:375-461.

8. Kramer HH, Trampisch HJ, Rammos S, Giese A. Birth weight of children with congenital heart disease. Eur J Pediatr. 1990;149:752-7.

9. Wernovsky G, Rubenstein SD, Spray TL. Cardiac surgery in the lowbirth weight neonate. New approaches. Clin Perinatol. 2001;28:249-64.

10. Chang AC, Hanley FL, Lock JE, Castaneda AR, Wessel DL. Management and outcome of low birth weight neonates with congenital heart disease. J Pediatr. 1994;124:461-6.

11. Roussin R, Belli E, Bruniaux J, Demontoux S, Touchot A, Planche C, et al. Surgery for transposition of the great arteries in neonates weighing less than 2,000 grams: a consecutive series of 25 patients. Ann Thorac Surg. 2007;83:173-8.

12. Pizarro C, Davis DA, Galantowicz ME, Munro H, Gidding SS, Norwood WI. Stage I palliation for hypoplastic left heart syndrome in low birth weight neonates: can we justify it? Eur J Cardiothorac Surg. 2002;21:716-20.

13. Lacour-Gayet F, Clarke D, Jacobs J, Comas J, Daebritz S, Daenen W, et al. The Aristotle score: a complexity-adjusted method to evaluate surgical results. Eur J Cardiothorac Surg. 2004;25:911-24.

\section{Discussion}

Dr Scott M. Bradley (Charleston, $S C$ ). Chris, that was a very nice and very clear presentation. I want to commend you as a cardiologist for being willing to come and talk to a room full of surgeons. You and your coauthors have brought to us a large and multi-institutional examination of the effects of small patient size on the outcome of congenital heart operations.

Your finding on mortality after shunt placement is interesting. If one goes through your article and takes all of the patients weighing less than $2.5 \mathrm{~kg}$ undergoing a shunt placement, other than a Norwood procedure, hospital mortality was $18 \%$, a fairly striking figure, if not terribly surprising. 
From a practical standpoint, when we are confronted with a small baby with CHD, we, as surgeons, have at least 2 questions: What operation do we perform, and when do we perform it? In terms of timing, is it better to operate immediately or later, perhaps waiting for growth, which generally does not occur? Because your data do not include information on patients not undergoing operations, they cannot help us with this question.

The first question, choice of operation, applies to patients who can be either palliated or repaired. Therefore another interesting observation in your data is that if one looks at the patients who could have had either a shunt or a complete repair, namely tetralogy with either pulmonary stenosis or pulmonary atresia, when weight was less than $2.5 \mathrm{~kg}$, more patients had a shunt than complete repair; however, those repaired actually had a slightly lower mortality than the patients who were shunted. I realize that the patients in these 2 pathways are likely not comparable, but it does highlight the fact that palliation in low-birth-weight infants does not necessarily carry a lower early risk than complete repair.

I have 2 questions for you. The first regards prematurity, which obviously covaries with low weight. This raises the question of whether the increased risk that you describe is due to prematurity, low birth weight, or the 2 factors in some interacting fashion. Do your data allow you to address this question?

Dr Curzon. They do not. Unfortunately, at the time of our analysis, gestational age, and therefore getting into the question of prematurity, is not a component within the STS database, and we were therefore unable to adequately assess that question.

We did try and attempt to analyze age at the time of surgical intervention as another confounder, or variable, to try and get the idea of management strategies that would delay surgical intervention, but we were unable to do this as well.

Dr Bradley. Do you, or maybe Dr Jacobs, know whether prematurity will be included in the future iterations of the STS database?

Dr Jacobs. Absolutely, it has already been added, and the trick is getting it in the database and then getting everybody to fill it out.

Dr Bradley. My second question is more general. Your study is basically a univariate analysis of the effect of patient weight on mortality. You did break down patients on the basis of RACHS-1 and
$\mathrm{ABC}$ criteria. But given the list of data that you provided in your Methods section, would it have been possible for you and your coauthors to conduct a multivariate analysis that might have shed more light on other determinants of mortality and the relative importance of low birth weight?

Dr Curzon. Thanks, Dr Bradley; that is a great question, which we also attempted to address. We tried to conduct a multivariate analysis on possible confounders for mortality with potential data that should be contained within the STS database. Unfortunately, there is a fairly large percentage of missing data when it comes to preoperative risk factors, intraoperative complications, and postoperative complications, including things like ventilator management, length of time on inotropic support, and things of that nature. Because of this significantly high percentage of missing data, it made a multivariate analysis very difficult.

Dr Bradley. Therefore the issue is that the data fields exist, but they have just been incompletely submitted?

\section{Dr Curzon. Correct.}

Dr Graham R. Nunn (Westmead, New South Wales, Australia). I just noticed you did not include any premature ductus in this analysis, and I would be the first one to agree that they do not compare in a cardiac corrective way to the lesions that you have described, but they are a tool with which you can probe the prematurity issue quite well because it is a curative operation in a similar age and weight range. If we, as we will, find that the mortality there is $9 \%$ or $10 \%$ with a similar weight, it does throw more light onto the other factors that are involved in the more complex lesions that you are probing. After all, they share the same precipitous delivery, with its potential for cerebral trauma, and have the same immature lungs. They are managed in the same intensive care unit with the same intensivist and protocols and share the same cardiac anesthetic regimens and postoperative care in the same institutions as their more complex cardiac cousins.

Dr Curzon. That is an interesting idea. Thank you. We did exclude isolated patent ductus arteriosus as a diagnosis, but that is an interesting idea that you raise that could have helped us maybe with some of the limitations with gestational age/prematurity within the database. 